Original Article

\title{
Analysis of lower extremity side-reaching motion in junior high school baseball players
}

\author{
YASUhiro Endo, RPT, PhD ${ }^{1)^{*}}$, MasaAki SAKAmoto, RPT, $\mathrm{PhD}^{2)}$ \\ 1) Department of Rehabilitation, Sendai Seiyo Gakuin College: 4-3-55 Nagamachi, Taihaku-ku, \\ Sendai 982-0011, Japan \\ 2) Graduate School of Health Sciences, Gunma University, Japan
}

\begin{abstract}
Purpose] The aim of this study was to clarify the movement pattern of the pelvis and trunk of junior high school baseball players based on the lateral reach motion of the lower limb, which is related to poor pitching movement. [Participants and Methods] Twenty-five male students belonging to a baseball club participated in this study. Each participant performed the lower limb side reach movement in the standing position, during which the movements of the knee joint, hip joint, pelvis, and trunk were analyzed. [Results] A significant correlation was found between reach distance and reach leg hip abduction, supporting leg hip abduction, trunk side bending, and trunk tilt. We found a significant correlation between reach leg hip abduction and pelvic tilt and trunk side bending and between supporting leg hip abduction and pelvic tilt, knee valgus, and trunk side bending. Furthermore, we found a significant correlation between knee valgus and lower leg tilt and trunk tilt and between trunk side bending and pelvic tilt. [Conclusion] This study suggests that in the standing position movement at this age, the hip and trunk movements are related to and affect performance.

Key words: Motion analysis, Baseball, Dynamic balance
\end{abstract}

(This article was submitted Jul. 3, 2019, and was accepted Aug. 23, 2019)

\section{INTRODUCTION}

In baseball players, repetition of pitching motions produces an accumulating load on the body and can cause injury ${ }^{1)}$. Pitching is a complicated set of motions that transfers energy to the ball while shifting the center of gravity from a single leg position to the front, accompanied by rotation of the lower limbs, pelvis, trunk, and upper limbs ${ }^{2,3)}$. In young baseball players, excessive pitching and bad motion tend to cause damage to the shoulder and elbow ${ }^{4}$. Individuals of this age have relatively tight muscles and immature muscle strength ${ }^{5}$. Moreover, having a relatively more fragile body puts players at a higher risk of injury than adults. However, muscle strength and muscle flexibility does not necessarily have a direct association with the quality of the pitching motion. Moreover, some players experience a decline in basic exercise ability that is essential for an action such as pitching. Junior high school age is the time when the skills necessary for sports are acquired. However, in the current generation of children, even baseball players may not be practiced in basic actions, such as basic motion, running, and jumping6). Young baseball players' throwing behavior is different from adults. Although horizontal abduction of the shoulder joint and flexion of the trunk are shown ${ }^{7)}$, the characteristics of the hip, pelvis, and trunk movement patterns have not been clarified. To understand the causes of injuries and to prevent these injuries in this player cohort, when evaluating pitching motion, it is necessary to evaluate the functional movements that simplify the operation. In a previous study, the Star Excursion Balance Test (SEBT), which evaluates dynamic standing balance, showed that athletes with larger reach distances have a higher risk of injury ${ }^{8}$. From these results, we considered that dynamic balance evaluation requires not only quantitative analysis of reach distance but also motion analysis.

*Corresponding author. Yasuhiro Endo (E-mail: ys_endou@seiyogakuin.ac.jp)

(C2019 The Society of Physical Therapy Science. Published by IPEC Inc.

(c) (1) $\odot$ This is an open-access article distributed under the terms of the Creative Commons Attribution Non-Commercial No Derivatives

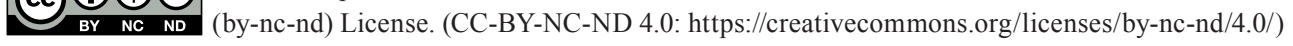


Therefore, the aim of this research was to clarify the movement pattern of the pelvis and trunk of junior high school baseball players using the lateral reach motion of the lower limb, which will be related to the poor pitching movement, which is a major factor of throwing disorder.

\section{PARTICIPANTS AND METHODS}

Overall, 25 male students belonging to a baseball club (mean age, $13.4 \pm 0.5$ years; height, $158.9 \pm 5.9 \mathrm{~cm}$; weight, $49.8 \pm 5.5 \mathrm{~kg}$ ) participated in this study. None of the participants had suffered an injury in the past 6 months or had a self-reported disability in a lower extremity. Explain the purpose, content, privacy protection, interests and disadvantages, participation by free will, withdrawal of consent, disclosure of information to the target person, parents, and team manager in verbal and written terms. Each person signed their consent form and confirmed in writing that they agreed. The study conformed to the Declaration of Helsinki.

Each participant performed a task of maximally reaching the stride leg from the one leg position of the axial leg of the throw. Participants were instructed to be barefoot during the testing, with the foot position controlled by aligning the heel with the center of a grid and the great toe with an anteriorly projected line. Errors were recorded in the following instances: the hands did not remain on the hips, the position of the stance foot was not maintained, the heel did not remain in contact with the floor, or the participant lost balance during the trial. The participants completed three test trials. Leg length was used to normalize excursion distances by dividing the reach distance by the leg length.

The motion was recorded from the front using video, and the posture at the maximum reach was analyzed with the image analysis software Kinovea. The items analyzed were trunk tilt, pelvic tilt, trunk side bending with respect to the pelvis, hip joint abduction on both sides, supporting leg knee valgus, lower leg tilt, and reach distance (Fig. 1).

We calculated the bivariate correlations between each item using Spearman's rank correlation. Statistical analysis was performed using EZR ${ }^{9)}$ and $\mathrm{p}<0.05$ was considered significant in all analyses.

\section{RESULTS}

The maximum reach distance and each joint angle at that time are as shown in Table 1. There was a significant correlation between reach distance and reach leg hip abduction, supporting leg hip abduction, trunk side bending, and trunk tilt. In addition, a significant correlation was observed between the reach leg hip abduction and pelvic tilt and trunk side bending as well as between axial leg hip abduction and pelvic tilt, knee valgus, and trunk side bending. Furthermore, there was a significant correlation between knee valgus and lower leg tilt and trunk tilt as well as between trunk side bending and pelvic tilt (Table 2).

\section{DISCUSSION}

Dynamic balance is associated with performance and difficulties in sports players ${ }^{10}$. Dynamic standing balance is evaluated by observing jumping and leg reaching movements from a standing position represented by the Y Balance Test ${ }^{11)}$ and SEBT $^{12)}$. Culiver et al. ${ }^{13)}$ suggested that dynamic standing balance ability correlates with hip musculoskeletal characteristics and pitching kinematics. However, it has been suggested that in baseball players, the lack of dynamic balance ability does not necessarily directly increase the risk of obstacles to performance ${ }^{8)}$ and that dynamic balance ability is not directly related to maximal ball velocity and pitching accuracy ${ }^{14)}$. With regard to dynamic standing balance for SEBT, which is similar to
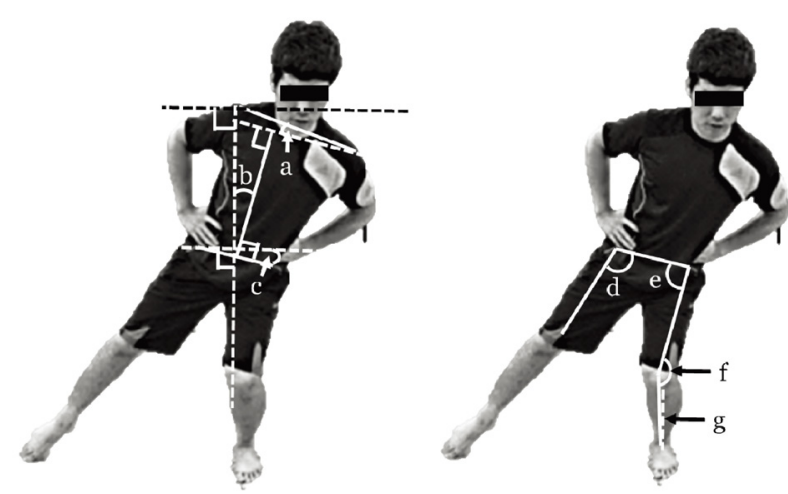

Fig. 1. Calculation method of each joint angle.

a: trunk side bending, b: trunk tilt, c: pelvic tilt, d: reach leg hip abduction, e: supporting leg hip abduction, f: supporting leg knee valgus, g: lower leg tilt. 
Table 1. Result of each angle at maximum side reach $(n=25)$

\begin{tabular}{lc}
\hline & Mean (SD) \\
\hline Reach distance & $0.82(0.14)$ \\
Reach leg hip abduction (degrees) & $20.82(5.87)$ \\
Lower leg tilt (degrees) & $0.63(10.10)$ \\
Pelvic tilt (degrees) & $12.61(4.76)$ \\
Supporting leg hip abduction (degrees) & $0.79(11.08)$ \\
Trunk side bending (degrees) & $-6.78(7.97)$ \\
Supporting leg knee valgus (degrees) & $10.06(14.13)$ \\
Trunk tilt (degrees) & $5.82(6.60)$ \\
\hline
\end{tabular}

Table 2. Correlations between each angle at maximum side reach $(n=25)$

\begin{tabular}{lccccccc}
\hline & $\begin{array}{c}\text { Reach leg } \\
\text { hip abduction }\end{array}$ & $\begin{array}{c}\text { Lower } \\
\text { leg tilt }\end{array}$ & Pelvic tilt & $\begin{array}{c}\text { Supporting leg } \\
\text { hip abduction }\end{array}$ & $\begin{array}{c}\text { Trunk side } \\
\text { bending }\end{array}$ & $\begin{array}{c}\text { Supporting leg } \\
\text { knee valgus }\end{array}$ & $\begin{array}{c}\text { Trunk } \\
\text { tilt }\end{array}$ \\
\hline Reach distance & $0.408^{*}$ & 0.175 & -0.045 & $0.548^{* *}$ & $0.408^{*}$ & -0.298 & $0.445^{*}$ \\
Reach leg hip abduction & & 0.073 & $-0.587^{* *}$ & -0.170 & $0.514^{* *}$ & -0.215 & 0.205 \\
Lower leg tilt & & & -0.273 & -0.178 & 0.195 & $0.515^{* *}$ & -0.018 \\
Pelvic tilt & & & & $0.471^{*}$ & $-0.430^{*}$ & -0.096 & 0.111 \\
Supporting leg hip abduction & & & & & 0.296 & $-0.701^{* *}$ & $0.644^{* *}$ \\
Trunk side bending & & & & & & -0.361 & $0.812^{* *}$ \\
Supporting leg knee valgus & & & & & & $-0.494^{*}$ \\
\hline
\end{tabular}

Spearman's rank correlation.

$* \mathrm{p}<0.05,{ }^{* *} \mathrm{p}<0.01$.

the motion task used in this study, a correlation between lower extremity muscle activation ${ }^{15)}$, range of motion ${ }^{16)}$ and reach distance has been reported. However, the movement strategy and degree of contribution of each joint have not yet been clarified. Therefore, when considering the relationship between baseball movements and dynamic balance, it is considered crucial to analyze the quantitative evaluation as well as the quality of movement. The ability to perform a large reach operation with a correct motion in a dynamic standing balance test indicates that the player's functional movement ability is good. In baseball, a good functional movement ability could lead to an effective pitching motion.

In the present study, movements that were correlated with reach distance were trunk side bending, body trunk tilt, reach leg hip joint abduction, and supporting leg hip abduction. It was observed that the reach distance achieved showed a proportional increase with the increase in angles of these factors. Therefore, to achieve a greater reach, it is necessary to brace the knee movement and the pelvic tilt and to generate a counterweight by tilting and side bending the trunk.

Hip joint abduction, which was correlated with reach distance, showed a significant negative correlation with pelvic gradient in both hip joints. The hip abduction of the reach leg was significantly correlated with the lateral trunk bending. The hip abduction of the supporting leg showed a significant positive correlation with the trunk tilt and a significant negative correlation with the supporting leg knee valgus. In other words, it was considered that the movement pattern that can increase the hip abduction in combination with the side bending of the trunk while keeping the pelvis parallel and controlling the valgus of the knee is the action that can increase the reach distance.

The characteristics of the throwing motion of young baseball players include a lack of rotation of the pelvis and trunk, a posterior pelvic tilt during the wind-up phase, and a lack of flexion of the hip and $\mathrm{knee}^{17}{ }^{18)}$. The movement pattern of the hip joint, pelvis, and trunk during the lower limb reach movement may be the same for the movement of the center of gravity forward in the cocking phase of the pitching movement. Evaluating the side reach motion may help to identify the points of the pitching motion that cause hindrances. It is highly probable that a person performing a reach movement using an inappropriate motion will fail to achieve an effective throw.

Although the results of this study do not pertain to a typical normal side reach motion, they show the characteristics of the lower limb reach movement of baseball players of junior high school age. The risk of injury tends to increase with increasing lower leg reach distance in dynamic standing. However, according to the results of this time, the lateral reach movement mainly focusing on hip abduction in a state where the pelvis cannot be kept in equilibrium, the knee valgus is large, and the lateral bending to the support side of the trunk is small, The movement may deviate from the typical movement pattern. In other words, in terms of the throwing motion, it may be a bad motion to move the center of gravity to the step side in a state where the motion patterns of these hip joints, pelvis, and trunk are deteriorated. Therefore, it is important to evaluate both the reach distance and the quality of motion.

Although it is impossible to examine the function with the techniques used in this investigation, it is evident that it is necessary to examine the factors contributing to bad performance, including cooperativeness and neurological factors of the lower limbs, pelvis, and trunk as well as the lower limb muscular strength and joint mobility range, both of which reportedly 
affect standing balance.

In the present study, the relationship between lower limb reach movement and injury occurrence was not investigated. Additional research is required to investigate the cause and effects of inappropriate movement, including its association with injury. In addition, in young individuals, further investigation of aspects such as movement learning and development in comparison with the effects of longitudinal direction as well as in comparison with adults is warranted.

\section{Presentation in a conference}

The part of our research was presented in the 29th Japanese Society of Clinical Sports Medicine congress (2018).

\section{Funding and Conflict of interest}

The authors declare no conflicts of interest associated with this manuscript.

\section{REFERENCES}

1) Agresta CE, Krieg K, Freehill MT: Risk factors for baseball-related arm injuries: a systematic review. Orthop J Sports Med, 2019 , 7: 2325967119825557. [Medline] [CrossRef]

2) Okamoto S, Endo Y, Saito R, et al.: Three-dimensional kinematic analysis of glenohumeral, scapular, and thoracic angles at maximum shoulder external rotation associated with baseball shadow pitching: comparison with normal pitching. J Phys Ther Sci, 2018, 30: 938-942. [Medline] [CrossRef]

3) Holt T, Oliver GD: Hip and upper extremity kinematics in youth baseball pitchers. J Sports Sci, 2016, 34: 856-861. [Medline] [CrossRef]

4) Melugin HP, Leafblad ND, Camp CL, et al.: Injury prevention in baseball: from youth to the pros. Curr Rev Musculoskelet Med, 2018, 11: 26-34. [Medline] [CrossRef]

5) Sakata J, Nakamura E, Suzukawa M, et al.: Physical risk factors for a medial elbow injury in junior baseball players. Am J Sports Med, 2017, 45: 135-143. [Medline] [CrossRef]

6) Gimenez R, Manoel EJ, de Oliveira DL, et al.: Integrating fundamental movement skills in late childhood. Percept Mot Skills, 2012, 114: 563-583. [Medline] [CrossRef]

7) Kageyama M, Sugiyama T, Kanehisa H, et al.: Difference between adolescent and collegiate baseball pitchers in the kinematics and kinetics of the lower limbs and trunk during pitching motion. J Sports Sci Med, 2015, 14: 246-255. [Medline]

8) Endo Y, Sakamoto M: Correlation of shoulder and elbow injuries with muscle tightness, core stability, and balance by longitudinal measurements in junior high school baseball players. J Phys Ther Sci, 2014, 26: 689-693. [Medline] [CrossRef]

9) Kanda Y: Investigation of the freely available easy-to-use software 'EZR' for medical statistics. Bone Marrow Transplant, 2013, 48: 452-458. [Medline] [CrossRef]

10) Gribble PA, Hertel J, Plisky P: Using the Star Excursion Balance Test to assess dynamic postural-control deficits and outcomes in lower extremity injury: a literature and systematic review. J Ath1 Train, 2012, 47: 339-357. [Medline] [CrossRef]

11) Shaffer SW, Teyhen DS, Lorenson CL, et al.: Y-balance test: a reliability study involving multiple raters. Mil Med, 2013, 178: 1264-1270. [Medline] [CrossRef]

12) Gribble PA, Kelly SE, Refshauge KM, et al.: Interrater reliability of the star excursion balance test. J Athl Train, 2013, 48: 621-626. [Medline] [CrossRef]

13) Culiver A, Garrison JC, Creed KM, et al.: Correlation among Y balance test- lower quarter composite score, hip musculoskeletal characteristics, and pitching kinematics in NCAA division I baseball pitchers. J Sport Rehabil, 2019, 28: 432-437. [Medline] [CrossRef]

14) Yanagisawa $\mathrm{O}$, Futatsubashi G, Taniguchi H: Side-to-side difference in dynamic unilateral balance ability and pitching performance in Japanese collegiate baseball pitchers. J Phys Ther Sci, 2018, 30: 58-62. [Medline] [CrossRef]

15) Earl JE, Hertel J: Lower-extremity muscle activation during the star excursion balance tests. J Sport Rehabil, 2001, 10: 93-104. [CrossRef]

16) Endo Y, Sakamoto M: Relationship between lower extremity tightness and star excursion balance test performance in junior high school baseball players. J Phys Ther Sci, 2014, 26: 661-663. [Medline] [CrossRef]

17) Thompson SF, Guess TM, Plackis AC, et al.: Youth baseball pitching mechanics: a systematic review. Sports Health, 2018, 10: 133-140. [Medline] [CrossRef]

18) Chalmers PN, Wimmer MA, Verma NN, et al.: The relationship between pitching mechanics and injury: a review of current concepts. Sports Health, 2017, 9 : 216-221. [Medline] [CrossRef] 